\title{
IMPORTANCE OF A TYPE OF GATING SYSTEM IN INVESTMENT CASTING TECHNOLOGY
}

\author{
OndŘej VRÁtný*, Aleš Herman \\ Czech Technical University in Prague, Faculty of Mechanical Engineering, Department of Manufacturing \\ Technology, Technická 4, 16607 Prague, Czech Republic \\ * corresponding author: ondrej.vratny@fs.cvut.cz
}

\begin{abstract}
At present, there is an increasing demand for the Investment casting technology. It is necessary to ensure their dimensional accuracy as well as internal quality and their desired macrostructure and microstructure. This paper deals with the issue of filling ceramic shells and their influence on the occurrence of oxide inclusions. The aim is to compare several proposed ceramic systems with top and bottom filling of a shell consisting of 4 blades and a gating system in terms of turbulence and monitoring of the contact line between the melt and the surrounded air.
\end{abstract}

KEYWORDS: Investment casting, gating system, oxide inclusion.

\section{INTRODUCTION}

Nowadays, a different types of numerical simulation software are widely used in a variety of manufacturing technologies, including the casting technology. A number of papers focusing on optimizing production processes using simulations in all casting technologies exists. This paper deals with the problem of gating systems and the related process of mould filling, because a well-designed gating system is very important to ensure a better quality of castings.

According to Sachin L. Nimbulkar and Rajendra S. Dalu, many researchers reported that $90 \%$ of the defects in casting are caused by an improper design of gating and feeding system. They deal with the problem of porosity in Design optimization of gating and feeding system through simulation technique for sand casting of wear. Porosity is one of the defects most frequently encountered in ductile iron casting and it impacts the costs by scrap loss and limits the use of cast parts in critical high strength applications [1]. However, cast iron was a subject of solution for Harshil Bhatt and his colleagues in the paper called Design optimization of feeding system and solidification simulation for cast iron. In this work they, focus on a problem of decision about a correct location of risers and the number of risers to be used during designing of the feeding system. For new castings or the castings having very high rejection rates, the modification of the feeding system design is of a prime importance [2]. Reactive materials and the problem of gassing systems is also addressed by Zhizhong Sun, Henry Hu and Xiang Chen. The various gating systems for a casting model of magnesium alloy were designed and simulated with the MAGMASOFT ${ }^{\circledR}[3$.

Very important author dealing, among other things, with the issues of filling forms is without a doubt John Campbell. In his book, Complete casting handbook: metal casting processes, metallurgy, techniques and design, there is, in detail, described the problem of melt flow and the importance of well-designed gating system with respect to the minimization of oxide inclusions, which is the aim of this paper [4].

In particular, the following authors also deal with simulations in the Investment casting technology:

Pei-Hsing Huang and Chi-Ju Lin are authors of Computer-aided modeling and experimental verification of optimal gating system design for investment casting of precision rotor. The requirements for a rotor production in the blood filter device during haemodialysis are very strict, especially due to the high frequency rotation. The rotor is made of stainless steel $(17 \% \mathrm{Cr}, 4 \% \mathrm{Ni}$ and $4 \% \mathrm{Cu})$. Shrinkage, porosity, or incomplete filling of the casting could lead to creep fractures. For this reason, computer-aided simulations are used to optimize the manufacturing process of the investment casting. During the research, the computer simulations were consistent with the real experiments. The simulations showed a rapid cooling problem when dynamic viscosity dropped rapidly. The result was insufficient filling in the interdendritic space. With a suitably designed gating and risers, the problem of material insertion and the turbulent flow of the melt have been almost eliminated, thus the surface droppings and internal shrinkage have disappeared [5].

Another paper called Simulation of $\mathrm{Ni}_{3} \mathrm{Al}$ based Alloy and Investment Casting Process of its Thin Wall Castings by Xi-e Zhang and his colleagues deals with complex thin-walled castings made of $\mathrm{Ni}_{3} \mathrm{Al}$-based alloy using the investment casting technology. Very often, manufacturers encounter defects in the form of non-filling of moulds or hot cracks. This article focuses on the obtaining of physical properties from both real measurements and a simulation software (JmatPro). This comparison gives credible results to be used as input data for a simulation of thin-walled castings in ProCast software. At the same time, the aim of the work is to optimize the gating system to 


\begin{tabular}{ll|ccccccccc}
\hline AISI 304L & & & & & & & & & & \\
\hline Element & & $\mathrm{C}$ & $\mathrm{Si}$ & $\mathrm{Mn}$ & $\mathrm{P}$ & $\mathrm{S}$ & $\mathrm{Cr}$ & $\mathrm{Ni}$ & $\mathrm{Co}$ & $\mathrm{Fe}$ \\
Content & Min & & & & & & 17 & 8 & & Bal. \\
[wt. \%] & Max & 0.03 & 2 & 1.5 & 0.04 & 0.04 & 21 & 12 & 0.05 & \\
\hline
\end{tabular}

TABLE 1. Chemical composition of the base (AISI 304L).

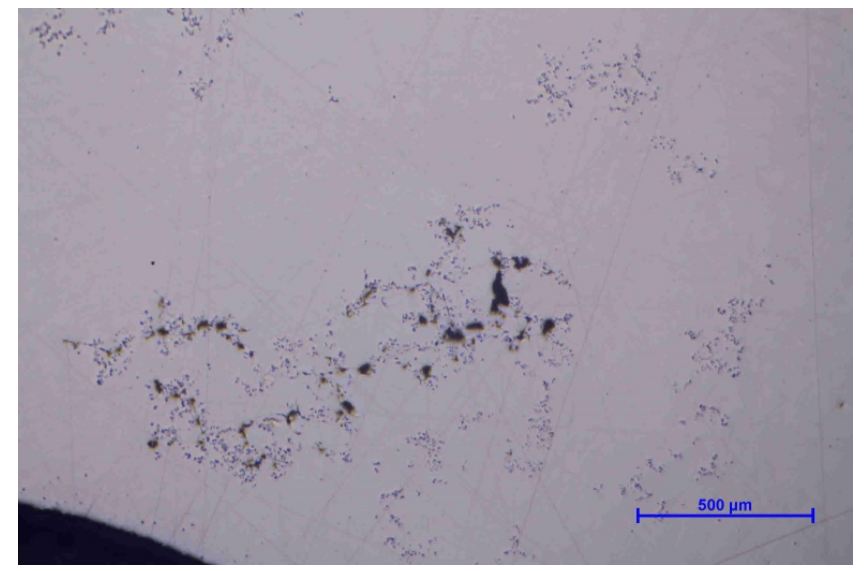

Figure 1. The analysis of oxide film (AISI 661).

reduce the occurrence of hot cracks and to ensure the smooth filling of the mould [6].

Use of ProCAST software to model casting systems for the centrifugal casting of GTE blades made of intermetallic alloys by V.V. Smirnov and colleagues focuses on the issue of the design of ceramic moulds for castings made of intermetallic titanium alloys (TiAl) casted by the investment casting technology. Computer simulations are used to analyse the filling of existing gating systems and especially to design new types to optimize and reduce scrap. An interesting variation there is a one with parts of the inlet system known as "dampers", which reduce the velocity of the flow at centrifugal casting to such a value that filling is very similar to laminar flow [7].

As it will be described later in this paper, part of the main aim is a development of suitable sprue well. Papers dealing with the design of sprue wells exit, but mainly for castings in the jewellery industry. This research will, in the future, deal with the design of sprue well for castings in energy industry. One of the papers written by N. Thammachot, P. Dulyapraphant and E. L. J. Bohez is called Optimal gating system design for investment casting of sterling silver by computerassisted simulation. The aim of this work is to design an optimal gating system eliminating the non-filling of the mould. The new shape and size of the pouring cup, sprue and channels are designed and researched. A numerical simulation was used to model the filling process. An optimal solution is to streamline the melt flow and reduce the turbulent flow. To verify the results of the simulations, real experiments were carried out. The result of the work is the elimination of defects in the form such as non-filling and an increase of productivity [8].
The subject of the paper Computer optimization of vertical gating system designs by Arnaldo Alonso and Luis Franco is the selection of the most suitable of three variants of vertical gating system casted by the Investment casting technology. Individual variants were simulated in SolidCast, FlowCast and Opticast from Finite Solution Inc. (using the Finite Difference Method) in order to increase the yield of vertically situated jewellery production systems, improve the production productivity and promote a new product design [9].

\section{MATERIAL AND METHODS}

There exist are many ways how to fill a ceramic mould in the investment casting technology. A lot of foundries, even nowadays, do not realize the importance of calm laminar filling especially of superalloys inclinabled to go into the oxidize state. This work aims to optimize gating systems with regard to elimination of defects such as oxide inclusions.

The goal is to find an optimal and easy way how to fill the shell with, if possible, laminar flow of the molten metal. We suggested and constructed our own blade which is very similar to those used in the energy industry.

In the following sectionpart, there will be shown individual variants of filling four blades connected in a tree assembly by an alloy known under a trade name CF3 will be shown. This kind of material may be referred to as an stainless steel and according to standard it is also known as AISI 304L (Chemical composition is listed in Table 1 .

There is available a metallographic sample is available in the following Figure 1 that shows internal defects in castings. In the structure there are a lot 


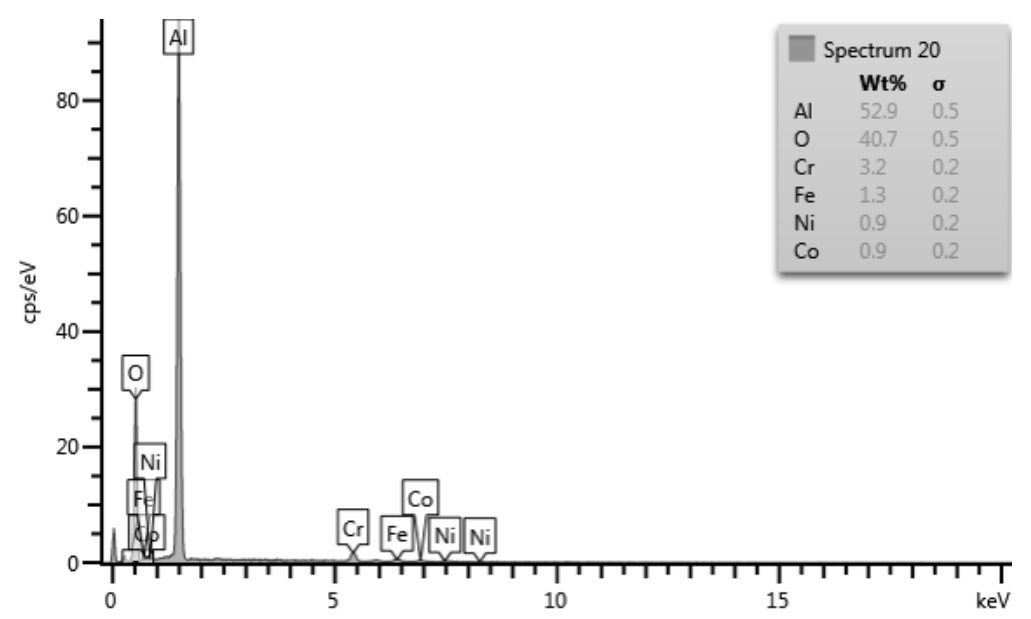

Figure 2. The chemical composition results of chosen area.

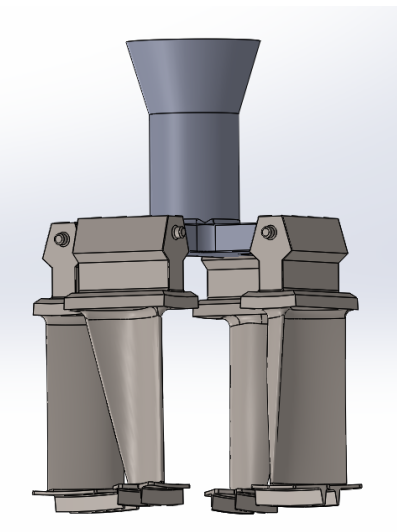

(A) . Variant A, B.

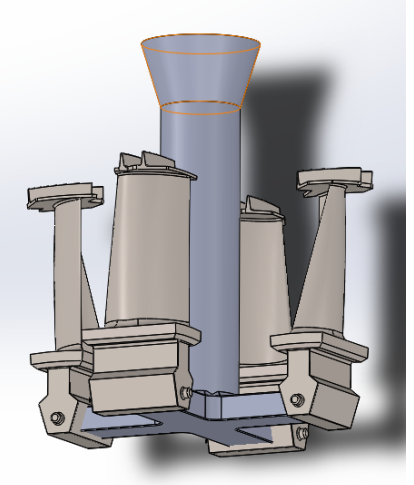

(D) . Variant E.

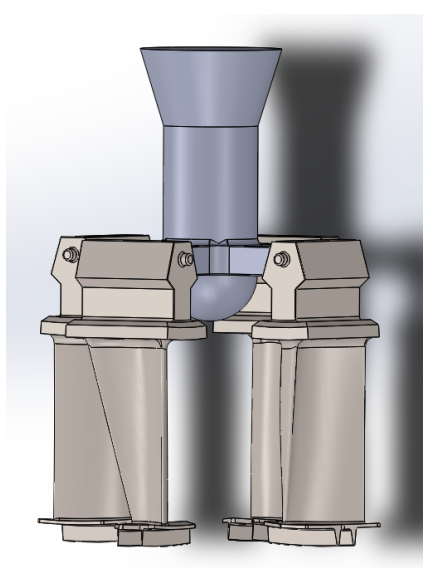

(B) . Variant C.

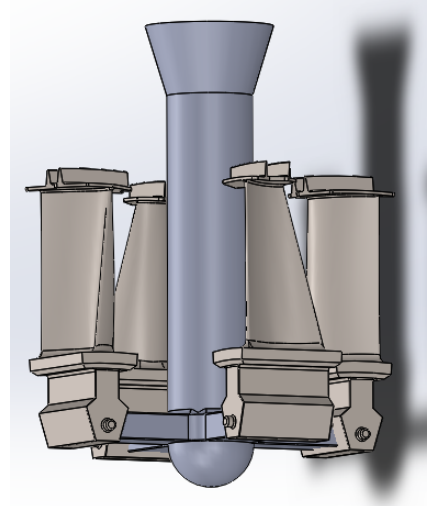

(E) . Variant F.

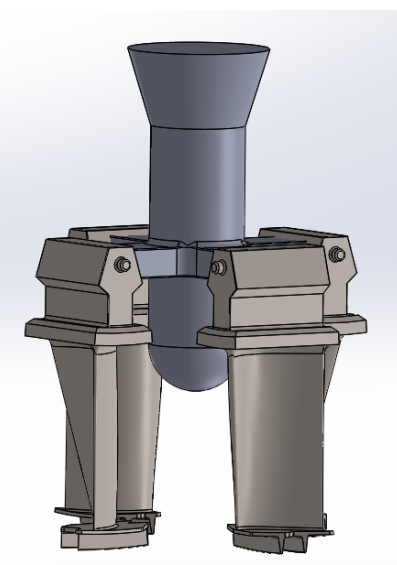

(c) . Variant D.

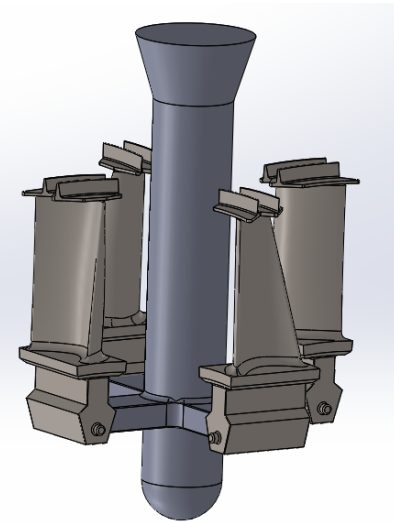

(F) . Variant G.

FiguRE 3. An overview of shell filling variants. 


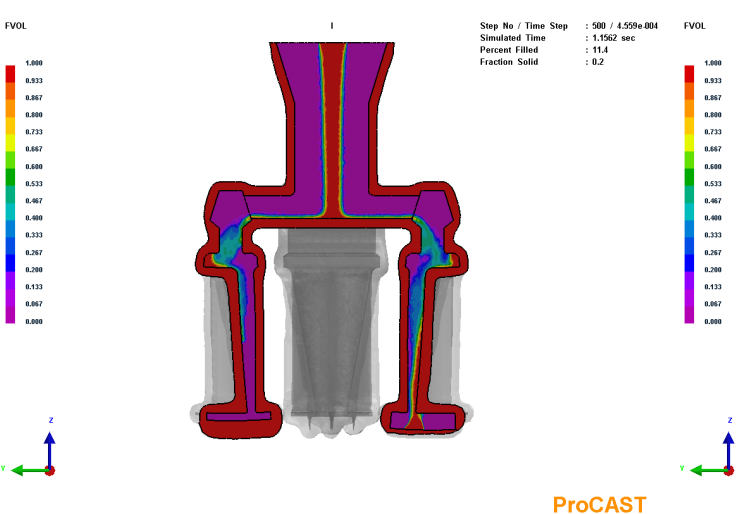

(A) . Filling process_step1A.

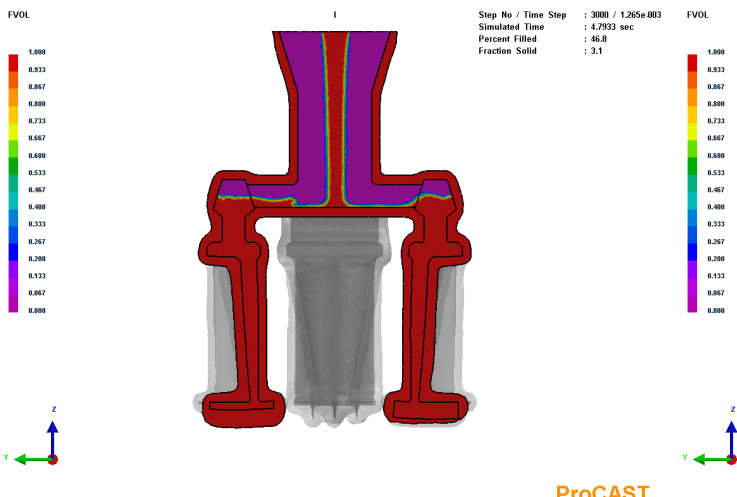

(c) . Filling process_step3A.

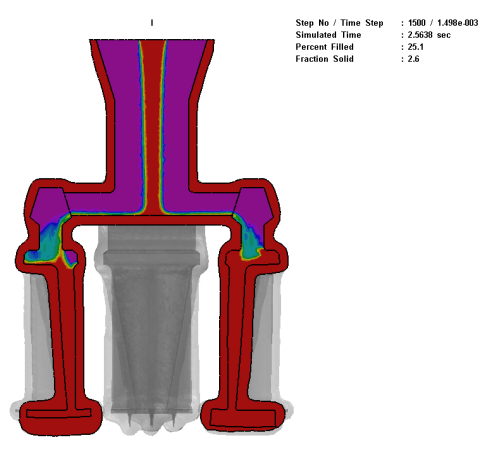

ProCAST

(В) . Filling process_step2A.

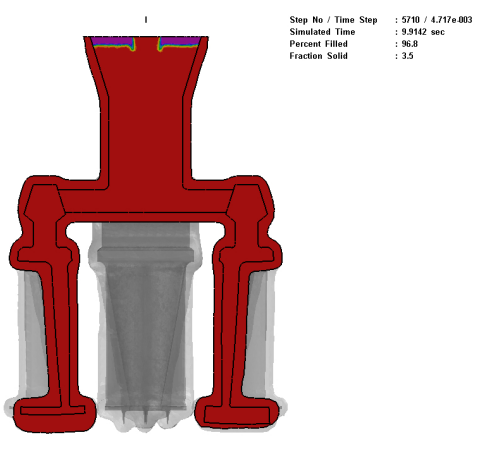

ProCAST

Figure 4. Filling process - Variant A

of inclusions formed in the shape of membrane are in the structure. It means, that they must develop as a film on the melt and then infiltrate in the casting. There are also inclusions of another shape. However, the samples show a lot of oxide films and probably some other much smaller inclusions around, developed probably from destroyed films.

This is a reason why it is important to optimize the casting process with a view focus to reducing these types of defects, which could reduce mechanical properties at higher temperatures and may also cause a number of other defects.

The analysis of AISI 304L in Figure 2 shows an increased content of aluminium and oxygen, occurring probably in oxidized state as $\mathrm{Al}_{2} \mathrm{O}_{3}$.

Variants A, B, C and D are top-filled. The main difference is in the size of the sprue well as shown in Figure 3 Variants E is equivalent to Variant A and B except that it is bottom-filled. The same applies to Variants F and C, G and D.

\section{Results AND Discussion}

\subsection{VARIANT A}

The first variant shown in the following pictures is very easy and a lot of foundries prefer this kind of gating especially because it is the cheapest one and very comfortable for preparing. The input data of simulation for variant A were estimated:

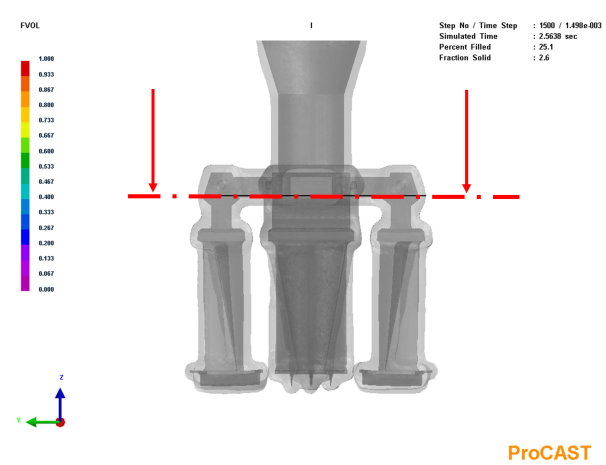

Figure 5. Cut indication for Figure 6

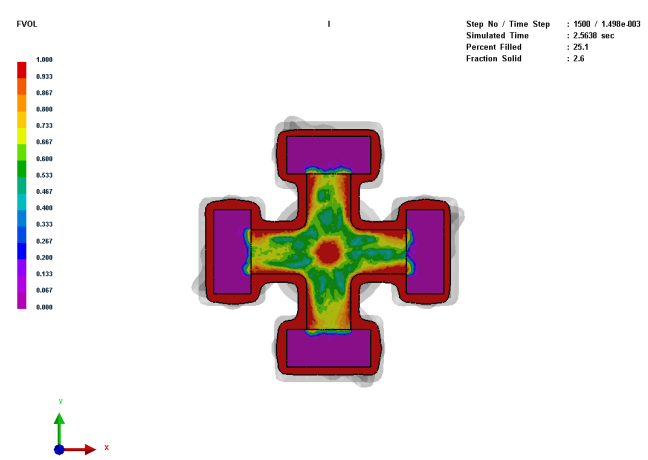

ProcAsT

FiguRE 6. Extensive border between melt and surrounded air. 


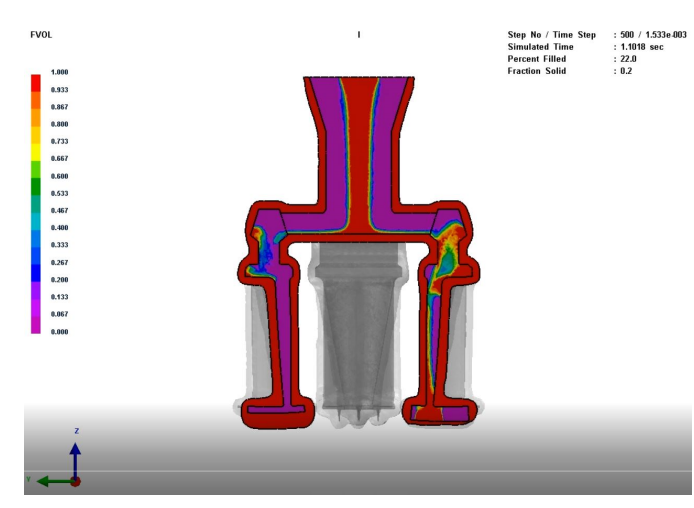

(A). Filling process_step1B.

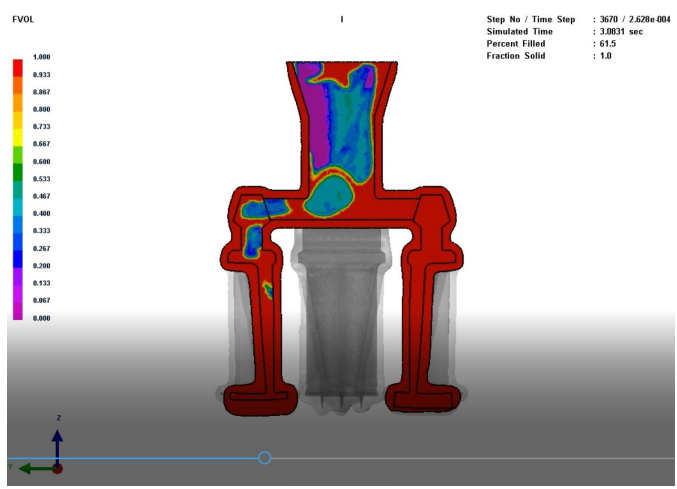

(C) . Filling process_step3B.

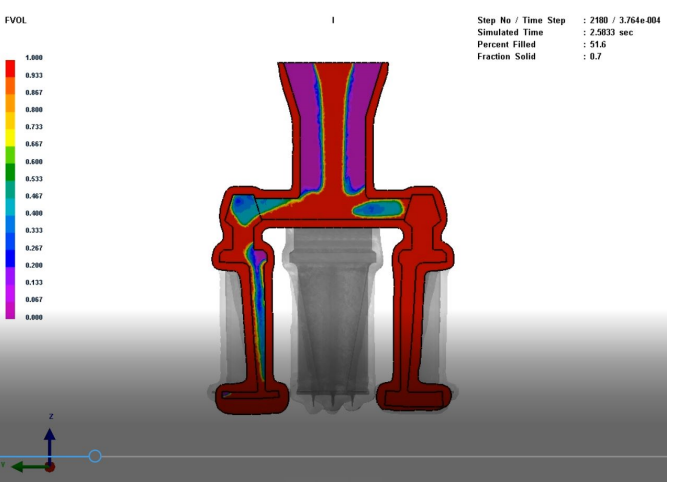

(В) . Filling process_step2B.

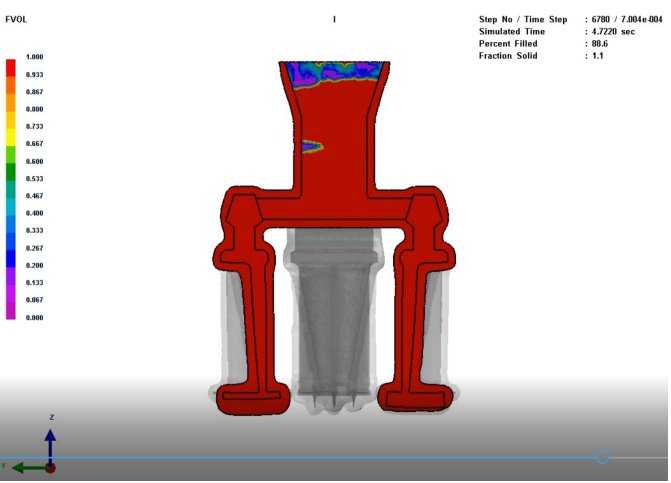

(D) . Filling process_step4B.

FIGURE 7. Filling process - Variant B.

Material:

Temperature of ceramic shell (Preheat):

CF3 (AISI 3041)

Temperature of molten metal

(Casting temperature):

Filling time:

\section{$1100{ }^{\circ} \mathrm{C}$}

$1500{ }^{\circ} \mathrm{C}$

10 seconds

The whole filling process took about 10 seconds it was too much, the following simulations were shortened. In the Figure $4 \mathrm{a}$ - Figure $4 \mathrm{~d}$, there is an emphasized contact between the melt and surroundings. The FVOL parameter used to compare individual variants of gating systems is a shortcut of Fraction of Volume. It indicates, in colour, the amount of the melt present in each element. Red colour is full filled. This parameter shows the contact between the melt and air in the mould.

As it is seen especially in the Figure 6, the contact border between the melt and surrounded air is very extensive. This figure is also related to the Figure $4 \mathrm{a}$ or Figure $4 \mathrm{~b}$, where it is shown how thin the layer of the melt is. It means that the flow of molten metal has a very large surface, which is able to react with the oxygen contained in air. This is the cause of oxide films, which are then, thanks to turbulent flow, sucked into the casting. However, this is a variant with very low flow, with about 10 seconds needed for filling 3.31 mould with molten metal. The following variants will be filled in 5 seconds and the aim is to find some design elements ensuring calmer flow.

\subsection{VARIANT B}

The setting of all following variants of simulations remains the same and only the geometrical shape of shells is changed. Important input data are following:

Material:

CF3 (AISI 304l)

Temperature of ceramic shell

(Preheat):

$1100^{\circ} \mathrm{C}$

Temperature of molten metal

(Casting temperature):

$1500{ }^{\circ} \mathrm{C}$

Filling time:

5 seconds

Another important information includes an effort to obtain credible filling conditions and to get a real contact with the surrounding environment. Therefore, the tightness of the mould was set so the air could not go out from the shell properly. It can generally be assumed that this was a poorly prepared shell with a low air permeability. Following Figure $7 \mathrm{a}$ - Figure $7 \mathrm{~d}$ illustrate individual important steps during the mould filling.

Variant B is comparable to Variant A, since it is the same gating system with the only difference being the filling rate. In Variant A - cca 10 second, Variant B 5 second. The difference is obvious from the figures. Variant A is with a calmer flow but with a longer exposure time of the melt to the environment. The filling of the variant $B$ seems to be wilder with more turbulent character. Both variants are not suitable for filling the mould. 

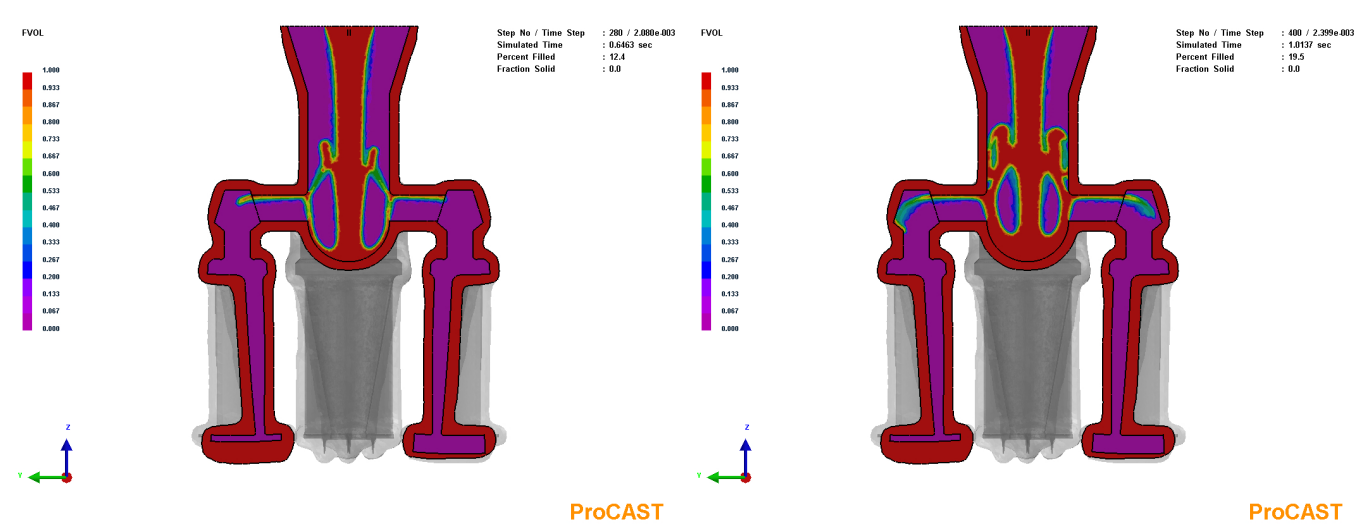

(A) . Filling process_step1C.

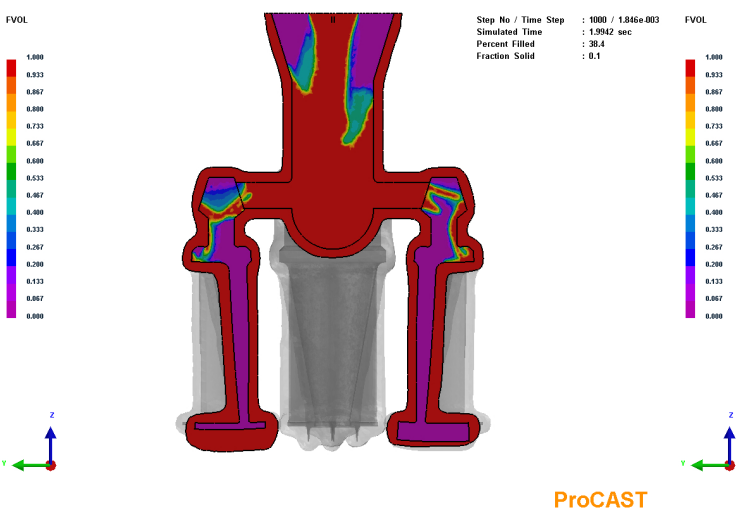

(B) . Filling process_step2C.

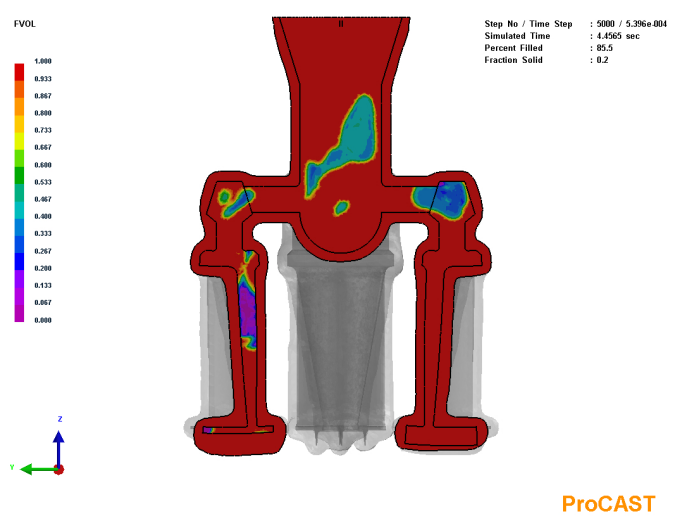

(C) . Filling process_step3C

(D) . Filling process_step4C.

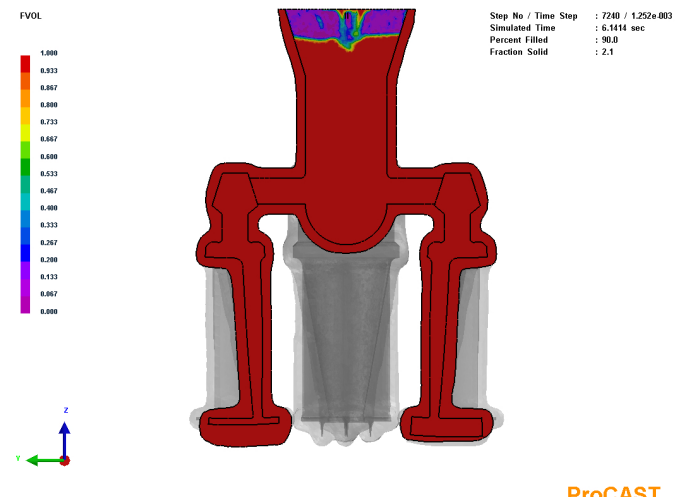

(E) . Filling process_step5C.

Figure 8. Filling process - Variant C. 


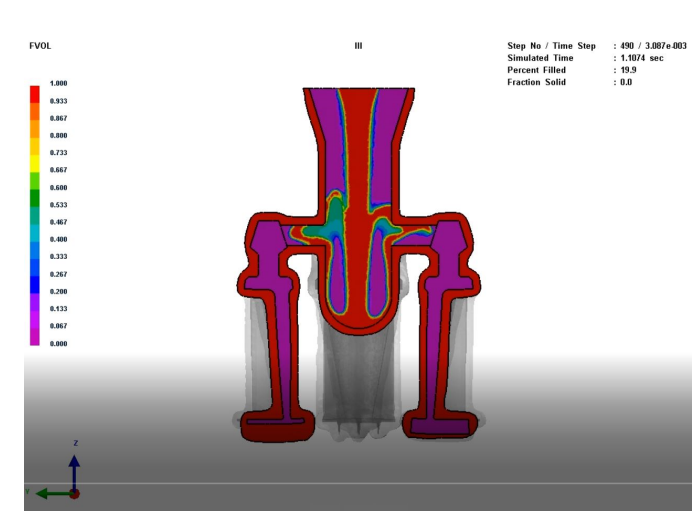

(A) . Filling process_step1D.

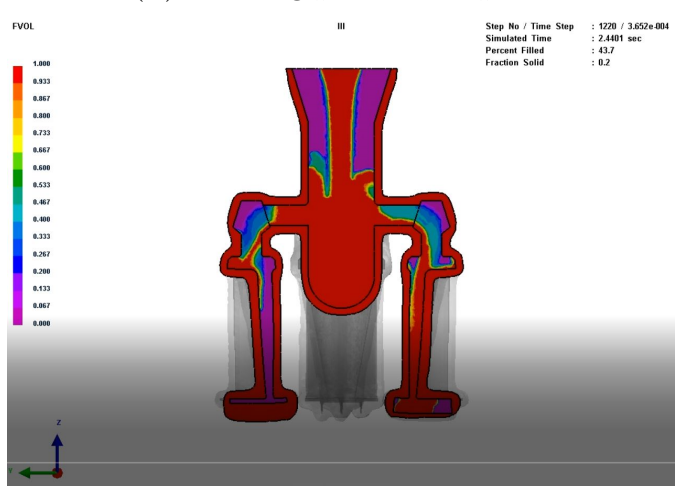

(C) . Filling process_step3D.

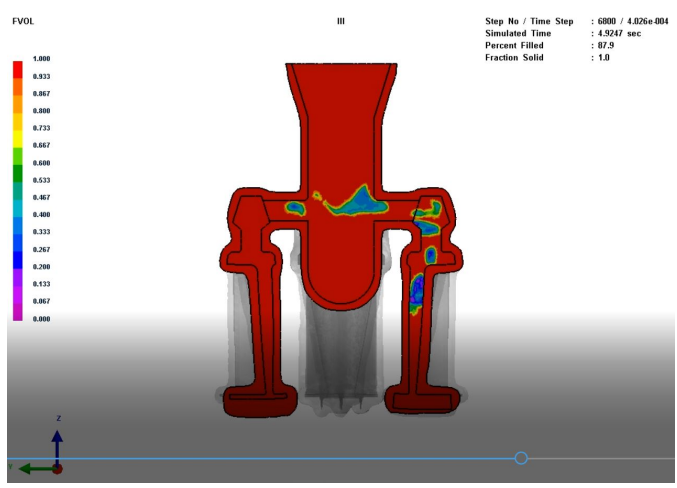

(E) . Filling process_step5D.

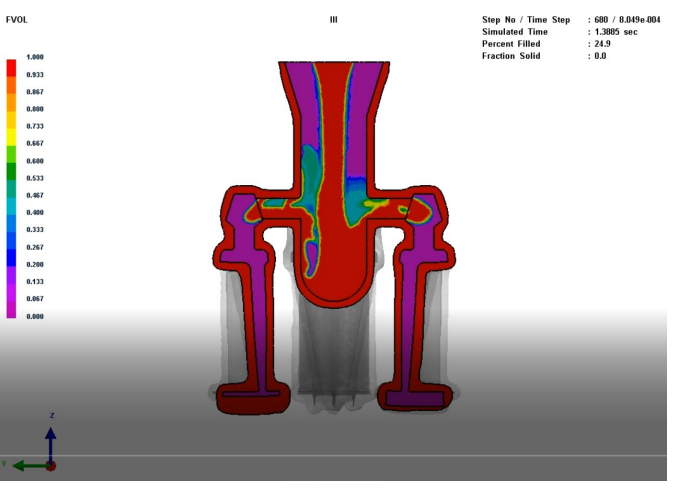

(в). Filling process_step2D.

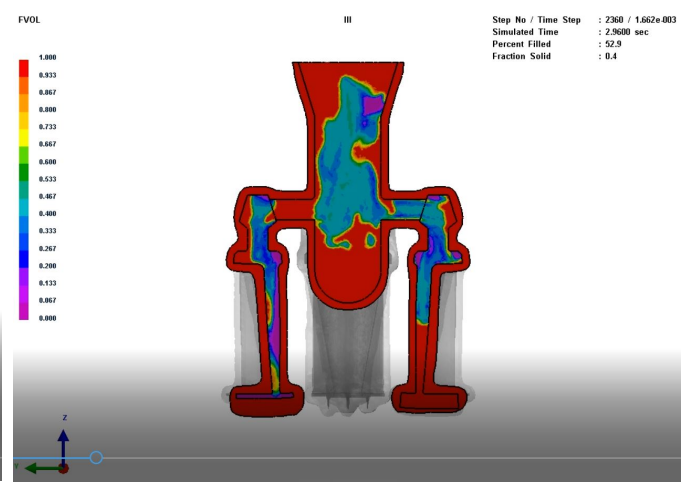

(D) . Filling process_step4D.

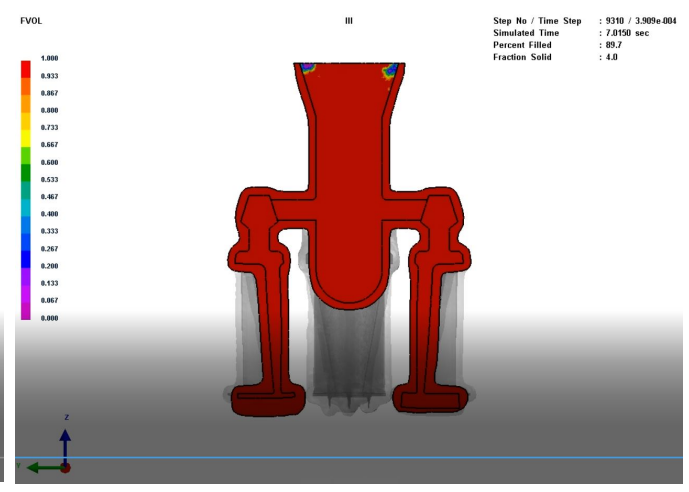

(F). Filling process_step6D.

Figure 9. Filling process - Variant D.

\subsection{VARIANT C}

A postulate for solving the problem of calmer filling was the design of a simple sprue well that would direct the molten metal in a suitable manner into the blades. Following Figure 8a - Figure 8e illustrate individual important steps during the mould filling of Variant C.

\subsection{VARIANT D}

Following Figure 9a - Figure 9f illustrate individual important steps during the mould filling of Variant D.

Variant C and Variant D show the comparison of two types of similar sprue wells differing in depth. The character of filling is in both variants very similar and the conclusion is that the filling shows worse results than Variants A and B. The postulate shall be correct but the shape of sprue well plays a larger role than originally assumed.

\subsection{VARIANT E}

The filling of precise castings could be divided into two basic groups. The first one, which was already mentioned in Variants A, B, C and D, is characterized by top filling. It means that castings are filled from the top to bottom of the part as shown in former Figures. The advantage of the top filling is, for example, faster filling of the mould, simpler design, easy way to achieve a rigid setting of castings to a tree. However, a very significant disadvantage is the turbulent flow, which plays an important role in the case of alloys inclinable to oxidation.

The second group of castings are filled from the bottom to the top of the part. The bottom filling ensures a laminar flow which is required by castings of superalloys and high alloy steels. The disadvantage in terms of production is mainly the more complex 


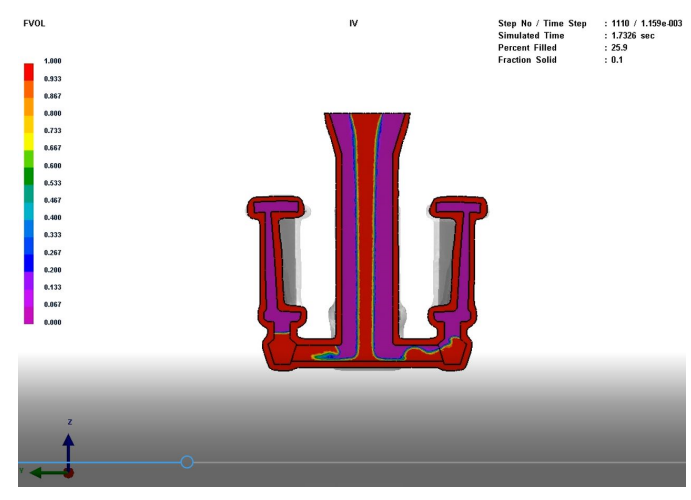

(A) . Filling process_step1E.

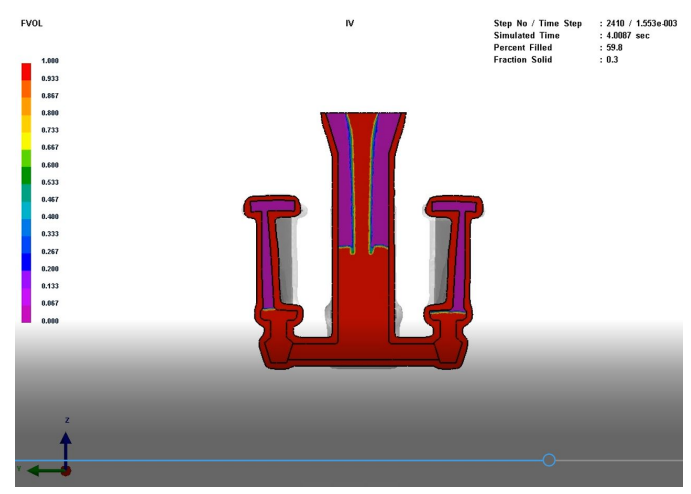

(c) . Filling process_step3E.

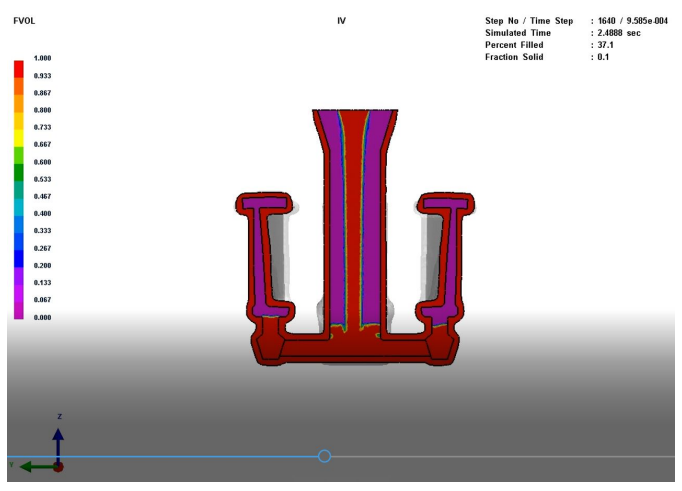

(B) . Filling process_step2E.

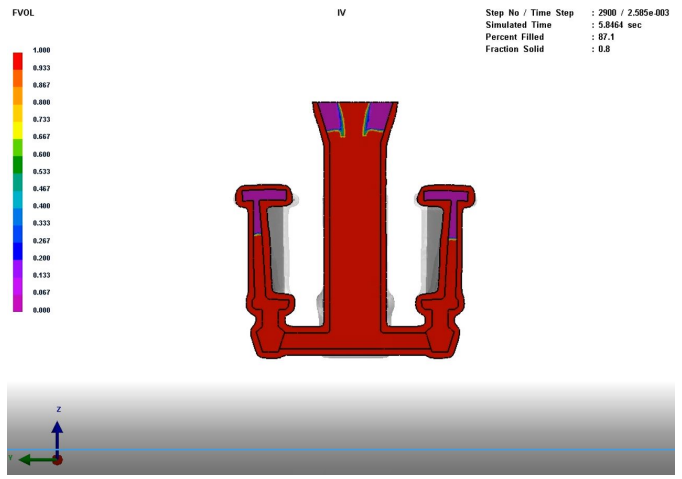

(D) . Filling process_step4E.

Figure 10. Filling process - Variant E.

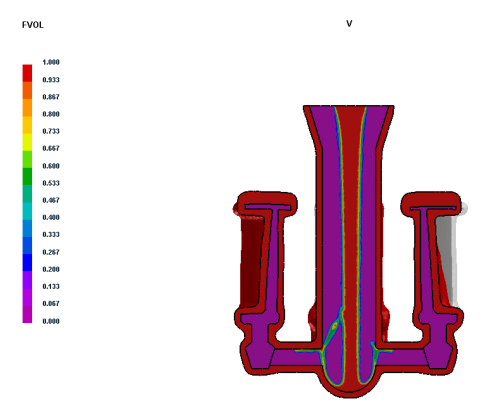

$\stackrel{1}{\rightarrow}$

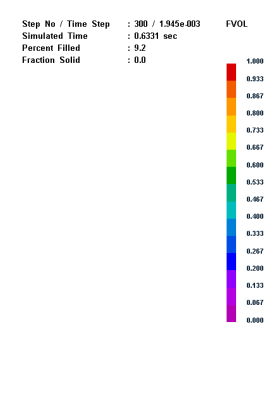

\llcorner

ProcAST

(A) . Filling process_step1F.

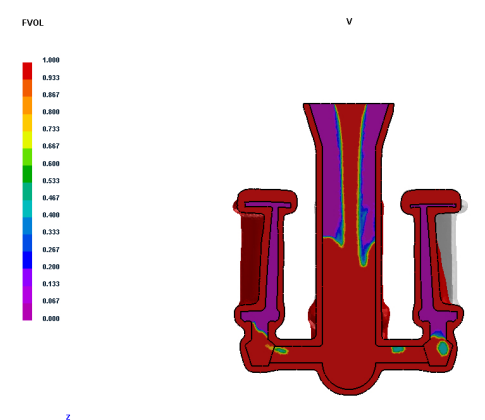

$\stackrel{1}{\longrightarrow}$

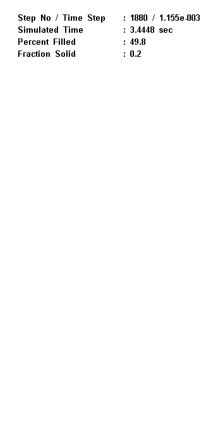

ProCAST

(c) . Filling process_step3F.

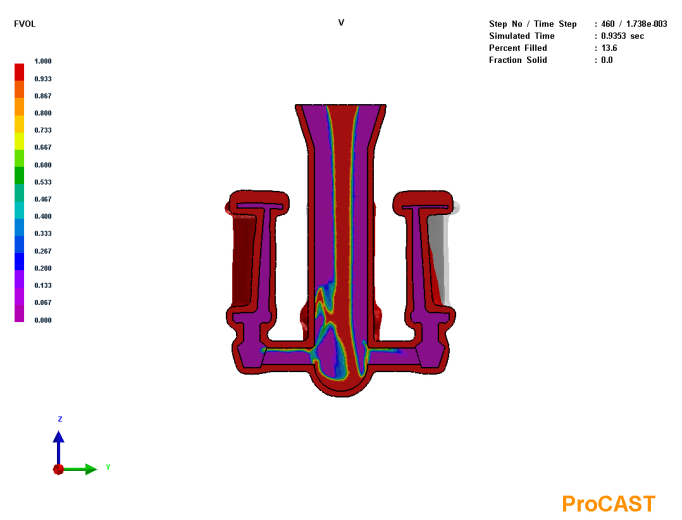

(B) . Filling process_step2F.

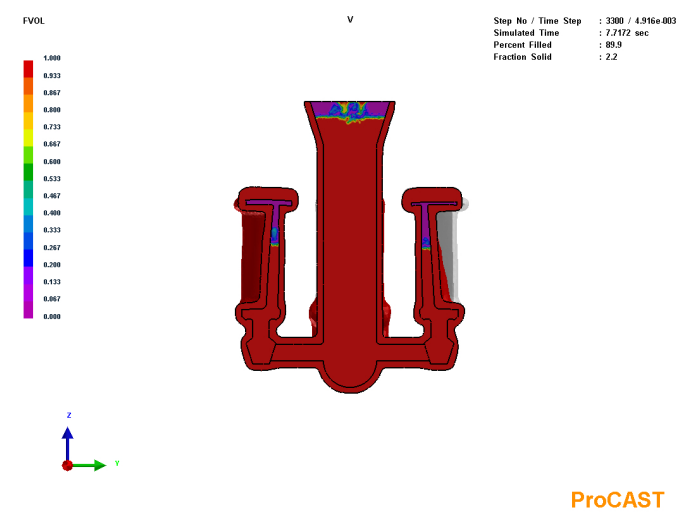

(D) . Filling process_step4F.

Figure 11. Filling process - Variant F. 


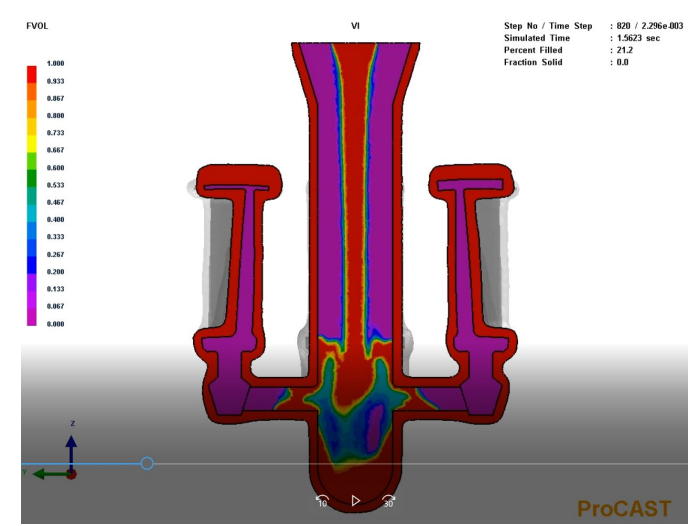

(A) . Filling process_step1G.

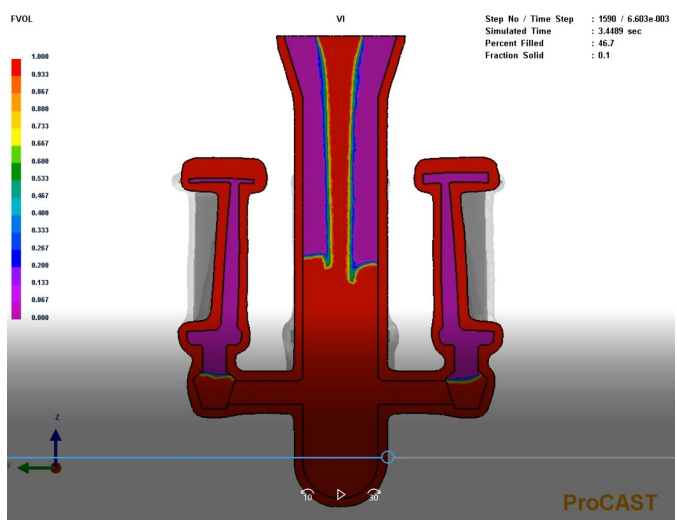

(C) . Filling process_step3G.

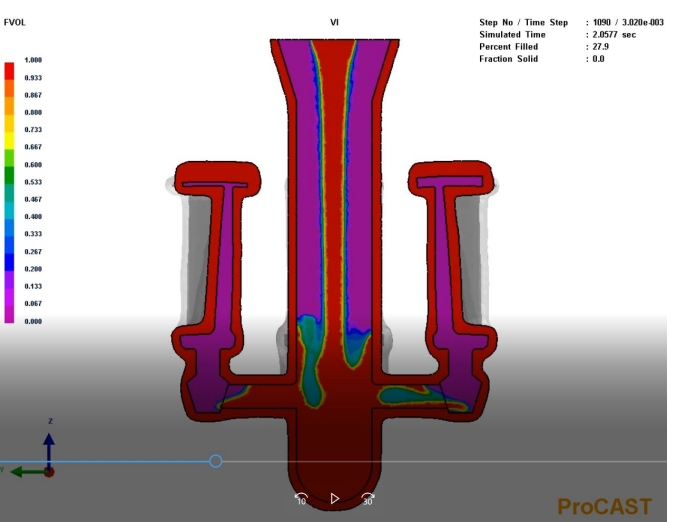

(B) . Filling process_step2G.

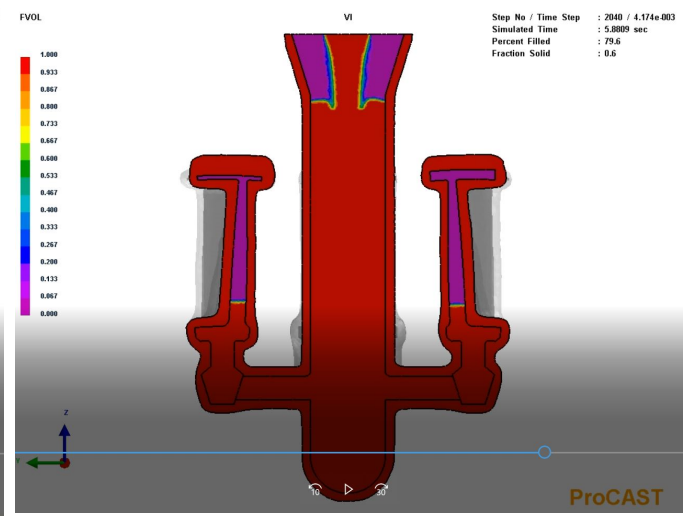

(D) . Filling process_step4G.

FiguRE 12. Filling process - Variant G.

and expensive preparation of shells. It is important to design a gating system with a sufficient strength to avoid deformations, especially in the case of coating wax trees in ceramic slurries.

The advantages and disadvantages of the top and bottom filling are only general postulates from literature and the whole research works on the optimization of the shell filling with regard to the reduction of the oxide inclusion.

Following Figure 10a - Figure 10d illustrate individual important steps during mould filling of Variant E.

Variant E is comparable to Variant B. The proportion and shape of the gating system is the same. The difference is only in the type of filling (top or bottom). In Variant G, a backwash of the melt occurs at the bottom of the gating system. This should cause problems with closing the air bubbles. However, the following filling from the bottom, in comparison to Variant B, shows signs of a smooth laminar flow. The closed air in the bandage area is the result of inappropriately selected input data of the simulation.

\subsection{VARIANT F}

Following Figure 11a - Figure 11d illustrate individual important steps during mould filling of Variant F.

\subsection{VARIANT G}

Following Figure 12a - Figure 12dillustrate individual important steps during mould filling of Variant $G$.

Assuming the aim of the variants $F$ and $G$ was, again, to improve the filling with the sprue wells as well as in Variants C and D. The conclusion is similar. The shape of sprue well plays very important role in the filling character. In all variants, resp. Variant C, $\mathrm{D}, \mathrm{F}$ and $\mathrm{G}$, the air bubbles are closed in the area of the sprue well due to the melt flow distribution and its re-coupling. This is not an acceptable option and the work will, in the next step, follow on this problem.

\section{Conclusion}

This article is a part of a wider research that focuses on the issue of filling ceramic shells. The aim of the entire work is to optimize the gating system in such a way so as to achieve filling ensuring a minimal contact between the melt and the surrounding environment to avoid the oxide inclusions. It is assumed, therefore, to cast in a free atmosphere, not in a vacuum.

There was no specific part for the energy industry that could be published, so it is necessary to create a new design that is similar to what is commonly used in practice. As an example, a blade was chosen, the use of which is wide, and casting foundries are trying to optimize these parts in terms of dimensional accuracy, 
internal quality and their desired macrostructure and microstructure.

The investment casting technology is a complicated and long process that should result in a high quality casting without defects. The influence of the design of the gating system on the quality of castings is a neglected topic especially because of the attribution of causes of defects to other influences. Many of authors deal specifically with this issue for a particular casting. The result of studies is mainly the following:

A simple design of the gating system is connected with ensuring that the melt is introduced into the thin casting walls even at lower casting temperatures.

The mould design must eliminate the turbulent flow and allow for a laminar flow of the melt.

The simulation results are verified with real casting results.

Specifically, this article focuses on the beginnings of optimizing the ceramic mould filling. From the proposed gating systems, we have confirmed the assumption that the bottom filling will run more smoothly than the top filling. However, it will be necessary to recalculate the cross-sections of the sprues, which are unnecessarily large for Variants A to G. This then results in phenomena, such as backwashes with a downstream fill without a sprue well, or the formation of a huge open surface that reacts with air oxygen generally in all variants.

Another important point is that it will depend largely on the shape of the sprue well that will be designed for each gating system. As a prerequisite, the idea of suppressing the turbulence caused by the flow directly from the basin remains a suitable sprue well, which will be the subject of a further research. The results from simulations will be, in the end, verified by a real casting process of chosen gating systems.

\section{ACKNOWLEDGEMENTS}

This publication was made possible by the Center advanced aerospace technologies, reg. No. CZ.02.1.01/0.0/0.0/16_019/0000826, which is cofinanced by the European Regional Development Fund through the Operational Program Research, development and education.

\section{REFERENCES}

[1] S. L. Nimbulkar, R. S. Dalu. Design optimization of gating and feeding system through simulation technique for sand casting of wear plate. Perspectives in Science 8:39 - 42, 2016. Recent Trends in Engineering and Material Sciences, DOI:10.1016/j.pisc.2016.03.001

[2] H. Bhatt, R. Barot, K. Bhatt, et al. Design optimization of feeding system and solidification simulation for cast iron. Procedia Technology 14:357 364, 2014. 2nd International Conference on Innovations in Automation and Mechatronics Engineering, ICIAME 2014, DOI:10.1016/j.protcy.2014.08.046

[3] Z. Sun, H. Hu, X. Chen. Numerical optimization of gating system parameters for a magnesium alloy casting with multiple performance characteristics. Journal of Materials Processing Technology 199(1):256 - 264, 2008. DOI:10.1016/j.jmatprotec.2007.08.036.

[4] J. Campbell. Complete casting handbook: metal casting processes, metallurgy, techniques and design. Elsevier Butterworth-Heinemann, 2011.

[5] P.-H. Huang, C.-J. Lin. Computer-aided modeling and experimental verification of optimal gating system design for investment casting of precision rotor. The International Journal of Advanced Manufacturing Technology 79(5):997 - 1006, 2015. DOI:10.1007/s00170-015-6897-5

[6] X.-e. Zhang, S. Li, X. Luo, et al. Simulation of Ni3Al-based alloy and investment casting process of its thin wall castings. Israel Journal of Chemistry 47:363 368, 2010. DOI:10.1560/IJC.47.3-4.363

[7] V. V. Smirnov, S. P. Pavlinich, S. V. Bakerin, A. M. Khairullina. Use of ProCAST software to model casting systems for the centrifugal casting of GTE blades made of intermetallic alloys. Metallurgist 57(11):961 - 964, 2014. DOI:10.1007/s11015-014-9829-y.

[8] N. Thammachot, P. Dulyapraphant, E. L. J. Bohez. Optimal gating system design for investment casting of sterling silver by computer-assisted simulation. The International Journal of Advanced Manufacturing Technology 67(1):797 - 810, 2013. DOI:10.1007/s00170-012-4523-3.

[9] A. Alonso, L. Franco. Computer optimization of vertical gating system designs. Foundry Management and Technology 133:22-24, 2005. 